\title{
Características produtivas do manjericão (Ocimum basilicum L.) em função do espaçamento entre plantas e entre linhas
}

\author{
FAVORITO, P.A. ${ }^{1}$; ECHER, M.M. ${ }^{2 *}$; OFFEMANN, L.C. ${ }^{1}$ SCHLINDWEIN, M.D. ${ }^{1}$; COLOMBARE, L.F. ${ }^{1}$; SCHINEIDER, \\ R.P.'; HACHMANN, T.L'. \\ ${ }^{1}$ Academicos do curso de agronomia da Universidade Estadual do Oeste do Paraná-UNIOESTE. ${ }^{2}$ Professora \\ adjunta do curso de agronomia/Centro de Ciências Agrárias.- UNIOESTE Rua Pernambuco, 1777, CP 1008, CEP \\ 85960-000, Marechal Cândido Rondon-PR.; e-mail:mmecher@bol.com.br²*; patimesmo@yahoo.com.br1.
}

RESUMO: O presente trabalho teve como objetivo avaliar o efeito de diferentes densidades de plantas nas características produtivas do manjericão (Ocimum basilicum L.), cultivado a campo. O experimento foi conduzido na estação experimental pertencente à UNIOESTE, em Marechal Cândido Rondon - PR, no período de setembro a dezembro de 2010. O delineamento utilizado foi 0 de blocos casualizados, em esquema fatorial $5 \times 2$, com três repetições. O primeiro fator foi constituído de cinco espaçamentos entre plantas $(0,10 ; 0,20 ; 0,30 ; 0,40 ; 0,50 \mathrm{~m})$ e o segundo de dois espaçamentos entre linhas de plantio $(0,20$ e $0,30 \mathrm{~m})$. As variáveis avaliadas foram altura de planta, diâmetro da copa, número de folhas, área foliar, massa fresca da parte aérea e das folhas, massa seca das folhas e das raízes, e determinadas a produção de massa fresca das folhas e da parte aérea. Os menores espaçamentos entre plantas e entre linhas proporcionaram maior produção de massa por área.

Palavras-chave: Ocimum basilicum L., densidade populacional, massa fresca.

\begin{abstract}
Productive characteristics of basil (Ocimum basilicum L.) as a function of spacing between plants and between rows. This study aimed to evaluate the effect of different plant densities on the yield characteristics of basil (Ocimum basilicum L.) cultivated in the field. The experiment was conducted at the experimental station belonging to UNIOESTE in Marechal Candido Rondon - PR for the period September to December 2010. The design was randomized blocks in a $5 \times 2$ factorial arrangement with three replications. The first factor consisted of five plant spacings $(0.10,0.20,0.30,0.40,0.50 \mathrm{~m})$ and the second of two planting spacings $(0.20$ and 0,30 $\mathrm{m})$. The smaller spacing between plants and between rows, to provide greater mass production by area.
\end{abstract}

Key words: Ocimum basilicum L., population density, fresh mass.

\section{INTRODUÇÃO}

O manjericão (Ocimum basilicum L.) segundo Rodrigues et al. (2005), é uma planta medicinal e aromática, originária da índia. Também denominada de alfavaca, alfavaca-cheirosa, basílico ou manjericão comum, é a espécie da família Lamiaceae mais intensamente cultivada no Brasil. Reis et al. (2007) relatam que sua implantação no país se intensificou após a chegada de imigrantes italianos, sendo que para este público a planta faz parte de uma tradição culinária muito forte.

A espécie caracteriza-se por apresentar ciclo anual ou perene, dependendo do local onde é cultivado ou de acordo com as características agronômicas observadas. Seu caule é ereto e ramificado e suas ramificações, segundo Simon (1985) citado por
Mathias (2010), podem atingir de 50 a $100 \mathrm{~cm}$ de altura. Suas folhas possuem coloração variada, a partir de tons de verde ou roxo, podendo ser lisas ou onduladas. As flores são pequenas e dispostas em racemos eretos, geralmente em grupos de três, podendo assumir tons de branco, lilás ou vermelho. O manjericão de folhas verdes é o mais conhecido e cultivado, e as espécies mais raras e mais aromáticas são as de folhas avermelhadas (Simon, 1985; Mathias, 2010).

Quanto ao clima, a cultura do manjericão se adapta a condições subtropicais ou temperadas, quente e úmido, podendo ser cultivado o ano todo. A planta tolera baixas temperaturas, porém seu desenvolvimento nessas condições é mais lento. É

Recebido para publicação: agosto de 2011

Aceito para publicação: dezembro de 2011

Rev. Bras. PI. Med., Botucatu, v.13, especial, p.582-586, 2011. 
sensível a geadas, sendo que a ocorrência da mesma em qualquer fase de desenvolvimento causa danos irreversíveis à planta.

As plantas medicinais, segundo Batalha et al. (2003) podem ser definidas como aquelas que possuem atividade biológica com um ou mais princípios ativos úteis à saúde humana, obtidos e elaborados exclusivamente a partir de matériasprimas ativas e vegetais. Características essas vantajosas para vários setores do mercado em todo o mundo. Corrêa \& Alves (2008) relatam também, que além do benefício relacionado à produção de fitoterápicos, a exploração das plantas medicinais oferece outras oportunidades, que abrangem desde a produção até o empacotamento. A maior parte da produção é comercializada "in natura", porém, pode ser também destinada a fins de extração de óleo essencial, indústrias de alimentos, bebidas e cosméticos, corantes, dentre outros.

A medicina alternativa utiliza as folhas e flores do manjericão para obtenção de chás por suas propriedades tônicas e digestivas, além de auxiliar no tratamento de problemas respiratórios e reumáticos. É também utilizado na culinária popular sob a forma de condimento, para tempero de omeletes, ensopados de carnes, peixes, frangos, saladas, sopas, recheios, como ingrediente principal em molho típico italiano, bem como em doces e licores.

No Brasil, a produção relacionada a plantas medicinais pode ser considerada vantajosa devido a biodiversidade vegetal que o país possui. Entretanto, pesquisadores como Corrêa \& Alves (2008), afirmam que investimentos e pesquisa relacionados à área, principalmente com relação à produção, industrialização e distribuição destas plantas, não tem sido tratados com a devida importância, dificultando assim etapas importantes relacionadas à estudos de potencialidades das espécies.

A produção brasileira de manjericão é praticada principalmente por pequenos produtores e é voltada para comercialização de folhas verdes aromáticas (May et al., 2008). Porém, existe em algumas região do nordeste, cultivos em maior escala voltados para produção de óleo essencial.

O óleo essencial do manjericão pode ser extraído de folhas e ápices que possuam inflorescências. Comumente este processo é realizado por meio de hidro destilação para obtenção de linalol. Atualmente este produto vem ganhando espaço também na agricultura devido à suas propriedades antimicrobianas, inseticidas e repelentes, sendo assim largamente usado como composto de partida para várias sínteses importantes, como a do acetato de linalila, sendo muito útil em operações curativas, preventivas e na conservação de grãos (Fernandes et al., 2004).
Quando se busca a otimização da produção, um dos primeiros pontos a considerar é o espaçamento ideal. Segundo Arismedi (1975), citado por Silva \& Casali. (2000), o espaçamento entre fileiras e entre plantas exerce grande influencia no comportamento das plantas, afetando-Ihes a arquitetura, desenvolvimento, massa, qualidade, e, dentre outras características, a mais importante que é a produtividade. No entanto, o aumento da produtividade por este método tem um limite, pois com o aumento na densidade populacional, cresce a competição entre plantas, sendo o desenvolvimento individual prejudicado (Minami et al., 1998). Assim, estudos relacionados à densidade de plantio têm por finalidade determinar o número de plantas capaz de explorar de maneira eficiente e completa uma determinada área de solo.

Considerando que as plantas podem apresentar uma competição intraespecífica e interespecífica pelos recursos do meio, Zanine \& Santos (2004) relatam que a competição pode ocorrer em duas dimensões diferentes de cultivo, que correspondem aos ambientes localizados abaixo e acima da superfície do solo. Estes autores afirmam que deve ser considerada também a associação entre os ambientes e que estes não devem ser manipulados de maneira isolada, pois as plantas com elevada habilidade competitiva acima do solo podem não dominar determinada área, se não possuírem suporte suficiente com relação aos recursos do solo e vice versa.

O arranjo de plantas é definido como padrão de distribuição das plantas em uma lavoura. Para melhor aproveitamento do espaço físico é importante conhecer a capacidade produtiva de uma espécie quando submetida a diferentes arranjos populacionais de plantas. Este importante aspecto pode variar em função do espaçamento entre plantas e entre linhas, o que vai determinar a densidade ideal de plantio.

O crescimento das plantas em um ambiente de competição pode também ser alterado devido à interferência gerada pelo efeito de sombreamento que ocorre entre e dentro das plantas, reduzindo, assim, o nível total de radiação solar para cada uma. Características como altura de plantas e área foliar podem influenciar na habilidade competitiva das plantas, alterando a penetração de luz, tanto no dossel da própria planta, quanto no de plantas vizinhas. Dessa forma, a altura e profundidade da copa poderiam ter aspectos relevantes na competição por luz e, consequentemente, nos padrões de coabitação das espécies (Zanine \& Santos, 2004).

Diante do exposto, considerando a escassez de estudos com manjericão, o presente trabalho teve como objetivo avaliar o efeito do espaçamento entre plantas e entre linhas, nas características produtivas do manjericão, cultivar 'Toscano folha de alface.

Rev. Bras. PI. Med., Botucatu, v.13, especial, p.582-586, 2011. 


\section{MATERIAL E MÉTODO}

O trabalho foi conduzido na Estação Experimental Prof. Dr. Antônio Carlos dos Santos Pessoa, pertencente ao Núcleo de Estações Experimentais (NEE) da Universidade Estadual do Oeste do Paraná, Campus de Marechal Cândido Rondon-PR, cujas coordenadas geográficas são: $24^{\circ}$ 33 ' de latitude sul, $54^{\circ} 31^{\prime}$ de longitude oeste e altitude de $420 \mathrm{~m}$. O solo é classificado como Latossolo Vermelho Eutroférrico de textura argilosa.

O clima local, segundo Köppen, é do tipo Cfa, subtropical com chuvas bem distribuídas durante $o$ ano e verões quentes. As temperaturas médias do trimestre mais frio variam entre $17 \mathrm{e}$ $18^{\circ} \mathrm{C}$, do trimestre mais quente entre 28 e $29^{\circ} \mathrm{C}$ e a anual entre 22 e $23^{\circ} \mathrm{C}$. A umidade relativa do ar anual está entre 70 a $75 \%$. Os totais anuais médios normais de precipitação pluvial para a região variam entre 1600 e $1800 \mathrm{~mm}$, com o trimestre mais úmido apresentando totais variando entre $400 \mathrm{e}$ $500 \mathrm{~mm}$ (IAPAR, 2010).

O delineamento experimental utilizado foi de blocos casualizados, em esquema fatorial $5 \times 2$, com três repetições. O primeiro fator foi constituído de cinco espaçamentos entre plantas $(0,10 ; 0,20$; $0,30 ; 0,40 ; 0,50 \mathrm{~m})$ e o segundo de dois espaçamentos entre linhas de plantio $(0,20$ e 0,30 $\mathrm{m})$ o que correspondeu à densidade de $500 ; 250$; $166 ; 125 ; 100 ; 333 ; 166 ; 111 ; 83$ e 66 mil plantas ha $^{-1}$, respectivamente. As parcelas foram constituídas de 16 plantas distribuídas em canteiros, com quatro linhas, sendo utilizadas para analisar as características produtivas, duas plantas centrais da parcela.

As mudas de manjericão, cultivar Toscano folha de alface, foram produzidas em bandejas de poliestireno expandido de 200 células contendo substrato comercial, mantidas em cultivo protegido até o transplantio, quando apresentaram quatro folhas completas, aos 30 dias após a semeadura. $A$ adubação de plantio foi realizada de acordo com análise de solo e com as recomendações de Biasi et al. (2009), com 100, 120 e $80 \mathrm{~kg} \mathrm{ha}^{-1}$ de N, $\mathrm{P}_{2} \mathrm{O}_{5}$ e $\mathrm{K}_{2} \mathrm{O}$, respectivamente. Na adubação de cobertura foram aplicados $50 \mathrm{~kg} \mathrm{ha}^{-1}$ e $45 \mathrm{~kg} \mathrm{ha}^{-1}$ de $\mathrm{N}$ em intervalos quinzenais. A irrigação foi realizada por aspersão e para amenizar o impacto da água com o solo e a emergência de plantas daninhas, sobre os canteiros utilizou-se palhada de aveia como cobertura morta.

As variáveis avaliadas foram: altura de planta, diâmetro da copa, número de folhas, área foliar, massa fresca da parte aérea e das folhas, massa seca das folhas, massa seca da parte aérea por planta e produção de massa fresca e seca de folhas e parte aérea por hectare. As avaliações foram realizadas aos 35 dias após o transplantio.
As variáveis, altura da planta e diâmetro da copa, foram mensuradas no campo com auxílio de uma régua graduada e as demais após a coleta das plantas. Após coletadas, as plantas foram acondicionadas em embalagens devidamente identificadas e levadas ao laboratório onde foram seccionadas, separando os diferentes órgãos da planta. Em seguida foi procedida a contagem das folhas, e determinada a massa fresca por pesagem em balança de precisão e posteriormente acondicionadas em sacos de papel e secas em estufa de circulação forçada de ar a $65^{\circ} \mathrm{C}$, até atingir massa constante. Com uma balança de precisão mensurou-se a massa seca da diferentes partes da planta.

Depois de tabulados, os dados foram submetidos á análise de variância e as médias comparadas pelo teste de Tukey, a $5 \%$ de probabilidade.

\section{RESULTADO E DISCUSSÃO}

A massa fresca das folhas e altura da planta não foram influenciadas pelo espaçamento entre plantas e entre linhas. Para as varáveis produção de massa fresca de folha e produção de massa fresca da parte aérea por área, os menores espaçamentos entre plantas e entrelinhas mostraram-se superiores.

Foram observadas diferenças significativas no espaçamento entre plantas para as variáveis diâmetro da copa, produção de massa fresca de folha e produção de massa fresca da parte aérea, por área. Sendo assim, estudou-se o efeito simples do fator. Pode-se observar que o diâmetro da copa no espaçamento de $0,30 \mathrm{~m}$ somente foi superior ao espaçamento de $0,20 \mathrm{~m}$. Contudo, a maior produção de massa fresca de folhas e produção de massa fresca da parte aérea por área foi observada no espaçamento de 0,10 m entre plantas, apesar de não se observar diferenças na massa fresca das folhas, conforme os resultados apresentados na Tabela 1. Estes resultados mostram que quando se considera a massa por planta isoladamente, o espaçamento mais indicado seria de 0,50 m entre plantas, pois haveria uma economia no custo de implantação da cultura. No entanto, quando se considera essa variável por área observa-se que há uma maior produção de massa fresca, tanto de folhas como de parte aérea, e uma maior eficiência no uso da área, repercutindo em maior renda para o produtor, visto que normalmente é uma cultura produzida em pequenas áreas. Segundo Lopes et al. (2011) e Biasi \& Deshamps (2009), os menores espaçamentos resultam em menor aproveitamento dos recursos do meio, não expressando o potencial genético da planta. 
TABELA 1. Diâmetro da copa (DC), massa fresca das folhas (MFF) por planta, produção de massa fresca das folhas (PMFF) e produção de massa fresca da parte aérea (PMFA) por área, em função do espaçamento entre plantas. Marechal Cândido Rondon, UNIOESTE, 2010.

\begin{tabular}{|c|c|c|c|c|}
\hline $\begin{array}{l}\text { Espaçamento entre plantas } \\
\qquad(\mathrm{m})\end{array}$ & $\begin{array}{c}\text { DC } \\
---\mathrm{cm}---\end{array}$ & $\begin{array}{c}\text { MFF } \\
---g \text {--- }\end{array}$ & $\begin{array}{c}\text { PMFF } \\
--- \text { t ha }^{-1}---\end{array}$ & $\begin{array}{c}\text { PMFA } \\
--- \text { t ha }^{-1}----\end{array}$ \\
\hline 0,10 & $25,65 \mathrm{AB}^{\star}$ & $36,18 \mathrm{~A}$ & $15,06 \mathrm{~A}$ & $18,99 \mathrm{~A}$ \\
\hline 0,20 & $24,98 B$ & $38,58 \mathrm{~A}$ & $7,99 \mathrm{~B}$ & $9,04 \mathrm{~B}$ \\
\hline 0,30 & $29,50 \mathrm{~A}$ & $42,35 \mathrm{~A}$ & $5,72 \mathrm{BC}$ & $6,90 \mathrm{BC}$ \\
\hline 0,40 & $26,48 \mathrm{AB}$ & $34,71 \mathrm{~A}$ & $3,62 \mathrm{C}$ & $4,56 \mathrm{CD}$ \\
\hline 0,50 & $25,80 \mathrm{AB}$ & $35,38 \mathrm{~A}$ & $3,05 \mathrm{C}$ & $3,66 \mathrm{D}$ \\
\hline CV (\%) & 12,77 & 16,42 & 22,04 & 18,85 \\
\hline
\end{tabular}

*Médias seguidas da mesma letra na coluna, não diferem entre si pelo teste de Tukey $(P \leq 0,05)$.

TABELA2. Diâmetro da copa (DC), massa fresca folhas (MFF) por planta, produção de massa fresca das folhas (PMFF) e produção de massa fresca da parte aérea (PMFA) por área, em função do espaçamento entre linhas. Marechal Cândido Rondon, UNIOESTE, 2010.

\begin{tabular}{|c|c|c|c|c|}
\hline \multirow[b]{2}{*}{ Espaçamento entre linhas (m) } & DC & MFF & PMFA & PMFF \\
\hline & --- cm --- & --- g --- & --- tha ${ }^{-1}$ & --- t ha ${ }^{-1}$ \\
\hline 0,20 & $26,79 A$ & $37,22 \mathrm{~A}$ & $9,97 \mathrm{~A}$ & $8,38 \mathrm{~A}$ \\
\hline 0,30 & $26,18 \mathrm{~A}$ & $37,67 \mathrm{~A}$ & $7,29 B$ & $5,79 B$ \\
\hline CV (\%) & 12,77 & 16,42 & 18,85 & 22,04 \\
\hline
\end{tabular}

*Médias seguidas da mesma letra na coluna, não diferem entre si pelo teste de Tukey $(P \leq 0,05)$.

Quanto ao espaçamento entre linhas, o menor espaçamento foi o que também apresentou maior produção de massa fresca de folhas e de parte aérea por área (Tabela 02).

Houve interação significativa entre espaçamento entre plantas e entre linhas para número de folhas, área foliar, massa fresca da parte aérea e massa seca das folhas. Na interação, dentro de cada espaçamento entre linhas, verificou-se que o espaçamento entre linhas de $0,30 \mathrm{~m}$ proporcionou maior número de folhas por planta quando 0 espaçamento entre plantas foi de $0,40 \mathrm{~m}$. Contudo, este diferiu significativamente apenas do espaçamento de $0,10 \mathrm{~m}$ entre plantas. Quanto à área foliar, massa fresca de parte aérea e massa seca de folhas, os maiores valores foram verificados com o espaçamento entre plantas de 0,30 m (Tabela 3). Esta resposta pode ser explicada pelo fato de que com o aumento da densidade de plantas até determinado ponto há maior exposição das folhas à luz difusa resultando no aumento da área foliar específica pela maior expansão foliar, desde que não haja comprometimento na produção de fotoassimilados por plantas.

Para o desdobramento da interação do espaçamento entre plantas dentro de cada espaçamento entre linhas não foi verificada superioridade para o número de folhas, área foliar, massa fresca da parte aérea e massa seca de folhas para o espaçamento entre linhas de 0,20 m.

Estes resultados podem ser explicados pelo fato de que menores densidades de plantio proporcionam maior numero de plantas por área, plantas estas que mesmo sofrendo maior pressão de competição geram um acumulativo final favorável à produtividade.

De acordo com a exigência do mercado, o produto pode ser comercializado em função da massa fresca e seca das folhas, bem como em maço. Quando se avalia isoladamente a planta a ser comercializada, pode-se utilizar qualquer espaçamento testado neste experimento, visto que não foram constadas diferenças entre os espaçamentos. No entanto, a utilização de espaçamentos maiores, ou seja, uma menor densidade de plantas por área, resulta em economia nos custos de produção, quando se avalia a massa por planta. Por outro lado, quando a comercialização for realizada por massa fresca, seca ou por maço de folhas, recomendase a utilização dos menores espaçamentos entre plantas e entre linhas, por proporcionar maior rendimento por área. 
TABELA 3. Número de folhas (NF), área foliar (AF), massa fresca da parte aérea (MFA), massa seca das folhas (MSF) por planta e produção de massa seca da parte aérea e massa seca das folhas por área, em função do espaçamento entre plantas e entre linhas. Marechal Cândido Rondon, UNIOESTE, 2010.

\begin{tabular}{|c|c|c|c|c|c|c|c|c|c|c|c|c|}
\hline \multicolumn{13}{|c|}{ Espaçamento entre linhas (m) } \\
\hline \multirow{3}{*}{$\begin{array}{l}\text { Espaçamento } \\
\text { entre plantas }(m)\end{array}$} & \multirow{2}{*}{\multicolumn{2}{|c|}{ NF }} & \multirow{2}{*}{\multicolumn{2}{|c|}{$\begin{array}{c}\mathrm{AF} \\
-\mathrm{cm}^{-2}--\end{array}$}} & \multirow{2}{*}{\multicolumn{2}{|c|}{$\begin{array}{l}\text { MFA } \\
-g--\end{array}$}} & \multicolumn{2}{|c|}{ MSF } & \multicolumn{2}{|c|}{ PMSF } & \multicolumn{2}{|c|}{ PMSA } \\
\hline & & & & & & & \multicolumn{2}{|c|}{$-\cdots g-\cdots$} & \multicolumn{2}{|c|}{$-\mathrm{t} \mathrm{ha}^{-1} \ldots$} & \multicolumn{2}{|c|}{$-\cdots$ tha-1... } \\
\hline & 0,20 & 0,30 & 0,20 & 0,30 & 0,20 & 0,30 & 0,20 & 0,30 & 0,20 & 0,30 & 0,20 & 0,30 \\
\hline 0,10 & $55,00 \mathrm{Aa}^{*}$ & $48,66 \mathrm{Ab}$ & $1513,86 \mathrm{Aa}$ & $1280,03 \mathrm{Ab}$ & 44,3Аa & $47,48 \mathrm{Aa}$ & 3,73Aa & $3,56 \mathrm{Ab}$ & 1,88Aa & $1,20 \mathrm{Ba}$ & $2,23 \mathrm{Aa}$ & $1,68 \mathrm{Ba}$ \\
\hline 0,20 & $50,16 \mathrm{Aa}$ & 57,83Aab & $1911,12 \mathrm{Aa}$ & $1519,10 \mathrm{Ab}$ & $40,74 \mathrm{Aa}$ & 47,39Aab & 4,24Aa & $3,99 \mathrm{Ab}$ & $1,07 \mathrm{Ab}$ & $0,67 \mathrm{Bb}$ & $1,11 \mathrm{Ab}$ & $0,79 \mathrm{Bb}$ \\
\hline 0,30 & $60,16 \mathrm{Aa}$ & $67,16 \mathrm{Aa}$ & $1590,02 \mathrm{Ba}$ & $2305,72 \mathrm{Aa}$ & $42,77 \mathrm{Ba}$ & $60,21 \mathrm{Aa}$ & 3,81Ba & $5,50 \mathrm{Aa}$ & $0,64 \mathrm{Ac}$ & $0,61 A b$ & $0,87 \mathrm{Ac}$ & $0,54 \mathrm{Bc}$ \\
\hline 0,40 & $53,50 \mathrm{Ba}$ & $71,33 \mathrm{Aa}$ & 1309,19Aa & $1527,18 \mathrm{Ab}$ & 43,97Aa & 43,58Aab & 3,52Aa & $3,77 \mathrm{Ab}$ & $0,44 \mathrm{AC}$ & $0,31 \mathrm{AC}$ & $0,58 \mathrm{Ad}$ & $0,54 \mathrm{Ac}$ \\
\hline 0,50 & $60,83 \mathrm{Aa}$ & 58,83Aab & $1805,43 \mathrm{Aa}$ & $1420,82 \mathrm{Ab}$ & $48,82 \mathrm{Aa}$ & $36,65 \mathrm{Bb}$ & 4,24Aa & $3,17 \mathrm{Bb}$ & $0,43 \mathrm{Ac}$ & $0,21 \mathrm{BC}$ & $0,43 \mathrm{Ad}$ & $0,31 \mathrm{Ad}$ \\
\hline $\mathrm{CV}(\%)$ & \multicolumn{2}{|c|}{11,25} & \multicolumn{2}{|c|}{17,03} & \multicolumn{2}{|c|}{14,98} & \multicolumn{2}{|c|}{10,98} & \multicolumn{2}{|c|}{9,42} & \multicolumn{2}{|c|}{14,99} \\
\hline
\end{tabular}

*Médias seguidas da mesma letra, maiúscula na linha e minúscula na coluna, não diferem entre si pelo teste de Tukey $(P \leq 0,05)$.

\section{CONCLUSÃO}

O adensamento para a cultura do manjericão pode ser uma estratégia para aumentos de produtividade;

-As maiores densidades de plantas proporcionam maior produção de massa fresca e seca de plantas por área.

\section{REFERÊNCIA}

BATALHA, M.O.; NANTES, J.F.D.;ALCANTRA, R.L.; MING, L.C.; DE CASTRO, D.M.; LOURENZANE, A.E.B.S.; MACHADO, J.G. de C.F.; RIBEIRO, P.M.T. Plantas medicinais no estado de São Paulo: Situação atual, perspectivas e entraves ao desenvolvimento. Florestar estatístico, v.6, n.15, 2003.

BIASI, L.A.; MACHADO, E.M.; KOWALSKI, A.P.J.; SIGNOR, D.; ALVES, M.A.; LIMA, F.I.; DESCHAMPS, C.; CÔCCO, L.C.; SCHEER, A.D.P. Adubação orgânica na produção, rendimento e composição de óleo essencial da alfavaca quimiotipo eugenol. Horticultura Brasileira, v.27, p. 35-39, 2009.

BIASI, L.A.; DESCHAMPS, C. Do cultivo à produção de óleo essencial. In: SOMMER, P.G. Manual de plantas aromáticas. Curitiba: Layer Studio Gráfico e Editora Ltda, 2009. p.100-103.

CORRÊA, C.C.; ALVES, A.F. Plantas medicinais como alternativa de negócio: caracterização e importância. Disponível em: <http://www.sober.org.br/palestra/9/ 418.pdf>. Acesso em 19 abr. 2011.

FERNANDES, P.C.; FACANALI, R.; TEIXEIRA, J.P.F.; FURLANI, P.R.; MARQUES, M.O.M. Cultivo de manjericão em hidroponia e em diferentes substratos sob ambiente protegido. Horticultura Brasileira. Brasília, v.22, p.260264, 2004.

IAPAR - INSTITUTO AGRONOMICO DO PARANÁ. Cartas climáticas do Paraná. Disponível em: <HTTP:// www.iapar.br/modules/conteudo.php?conteudo=863>. Acesso em: 20 abr. 2010.

JANICK, J.V.A. A ciência da horticultura. São Paulo: Freitas Bastos S.A, 1986. 486p.

LUPE, F.A.; BARATA, L.E. Plantas aromáticas da
Amazônia. 2007. 103p. Dissertação (Mestrado - Área de Concentração em Química Orgânica) - Instituto de Química, UNICAMP, Campinas.

LUZ, J.M.Q.; MORAIS, T.P.S.;BLANK, A.F.;SODRÉ, A.C.B.; OLIVEIRA, G.S. Teor, rendimento e composição química do óleo essencial de manjericão sob doses de cama de frango. Horticultura Brasileira, v.27, p.349-353, 2009. MATHIAS, J. Manjericão. Globo Rural. 2010. Disponível em: <http://revistagloborural.globo.com/globorural/ o,6993,EEC1669313-4529,00.html>. Acesso em 27 abr. 2010.

MAY, A.;TANAKA, M.A.S.; SILVA, E.H.F.M.;PINHEIRO, M.Q. Ocorrência de cercosporiose em Ocimum basilicum $L$. Centro de horticultura - Plantas Aromáticas e Medicinais. 2008. Disponível em: <http://www.iac.sp.gov.br/ Tecnologias/Aromaticas.htm>. Acesso em 29 abr. 2011. MINAMI, K.; CARDOSO, A.I.I.; COSTA, F.; DUARTE, F.R. Efeito do espaçamento sobre a produção em rabanete. Bragantia, v.57, p.169-173, 1998.

REIS, A.; MIRANDA, B.E.C.; BOITEUX, L.S.; HENZ G.P. Murcha do manjericão (Ocimum basilicum) no Brasil: agente causal, circulo de plantas hospedeiras e transmissão via semente. Summa Phytopathologica, v.33, n.2, p.137-141, 2007.

RODRIGUES MF; DOS SANTOS EC. Estudo da viabilidade financeira: implantação da cultura do manjericão para exportação. UPIS, 2005. Disponível em: <http:// http://www.upis.br/pesquisas/pdf/ agronomia/projeto_empresarial/pesquisas/ implantacao_manjericao1.pdf>. Acesso em 13 abr.2010.

SILVA, F.; CASALI, V.W.D. Plantas medicinais e aromáticas: Pós colheita e óleos essenciais. Viçosa: Arte e livros, 2000. 135p.

SILVA, L.C. Análise do Crescimento de Comunidades Vegetais. Circular técnica. Embrapa Algodão, v.1, n.34, 2000.

SIMON, J.E. Basil. West Lafayette: Purdue University, 1995. 6 p. (Boletim).

SIMON, J.E. Sweet basil: a production guide. West Lafayette: Purdue University, 1985. 3p. (Boletim).

ZANINEL, A.D.M.; SANTOS, E.M. Competição entre espécies de plantas - uma revisão. Revista da FZVA, v.11, n.1, p.10-30, 2004.

Rev. Bras. PI. Med., Botucatu, v.13, especial, p.582-586, 2011. 